\title{
Biatrial enlargement: an unusual cause of massive cardiomegaly
}

\author{
Tanupreet Sethi, ${ }^{1}$ Ajit Pal Singh, ${ }^{2}$ Vivek Singla, ${ }^{2}$ Yadvinder Singh ${ }^{2}$
}

${ }^{1}$ Department of Radiology, Kempegowda Institute of Medical Sciences, Bengaluru, Karnataka, India

${ }^{2}$ Department of Cardiology, Sri Jayadeva Institute of

Cardiovascular Sciences and Research, Bengaluru,

Karnataka, India

\section{Correspondence to} Vivek Singla,

drviveksingla98@gmail.com
To cite: Sethi T, Singh AP, Singla V, et al. BMJ Case Rep Published online:

[please include Day Month Year] doi:10.1136/bcr-2012008320

\section{DESCRIPTION}

A 50-year-old woman presented with complaints of progressive breathlessness and easy fatiguability over the past 2 years. Jugular venous pressure was raised with absence of a wave. Cardiac auscultation revealed two distinct mid-diastolic murmurs at the apex and a left lower sternal border with an ejection systolic murmur at the right second intercostal space. The ECG performed showed atrial fibrillation with a fast ventricular rate. Rate control was achieved with amiodarone infusion and intravenous diuretic therapy was instituted. Chest radiograph (figure 1) showed evidence of gross cardiomegaly (cardiothoracic ratio $=0.8$ ) with the left heart border touching the left lateral chest wall. Enlargement of the left atrium was evidenced by straightening of the left heart border, double density sign and splaying of the carina. Widening of the right heart border suggested right atrial enlargement. There was conspicuous absence of pulmonary congestion disproportionate to the severe symptomatic status. Aortic knuckle calcification was seen. A transthoracic echocardiogram (figures 2 and 3A-D) diagnosed the condition as chronic rheumatic heart disease with severe stenotic lesions of the mitral, tricuspid and aortic valves and mild regurgitation at the three valves. The left atrium measured $8.5 \mathrm{~cm} \times 5.8 \mathrm{~cm}$ in area while the right atrium measured $50.3 \mathrm{~cm}^{2}$.

Predominant biatrial enlargement can present as an unusual cause of massive cardiomegaly. Causes of

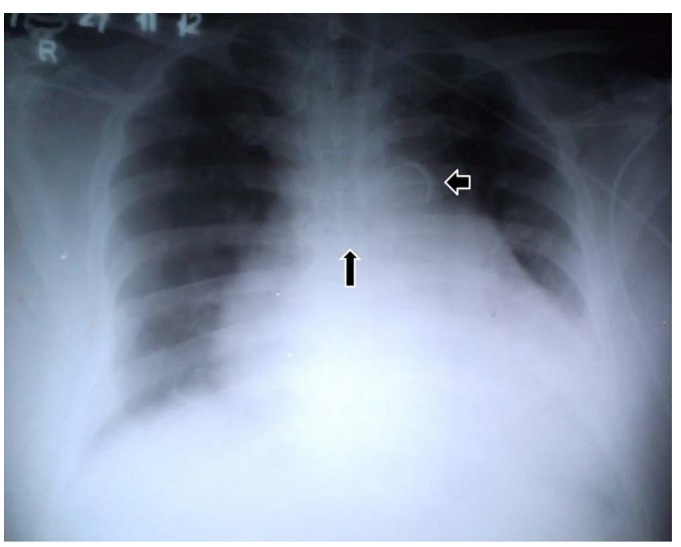

Figure 1 Chest radiograph showing massive cardiomegaly with signs of biatrial enlargement. Vertical arrow depicts carinal splaying, suggesting left atrial enlargement. Horizontal arrow shows aortic knuckle calcification.

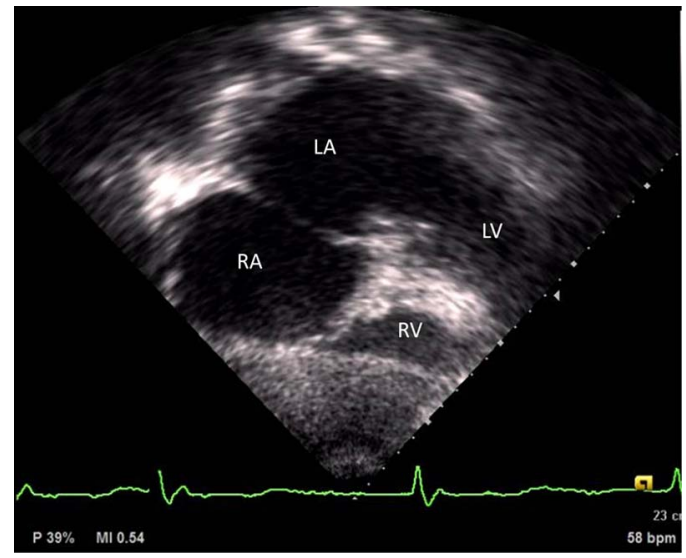

Figure 2 Transthoracic two-dimensional echocardiogram in a subcostal view depicting chamber enlargement as seen in the chest radiograph. LA, left atrium; $L V$, left ventricle; $R A$, right atrium; $R V$, right ventricle.

biatrial enlargement include restrictive cardiomyopathy, rheumatic heart disease, isolated mitral insufficiency and constrictive pericarditis. ${ }^{1}{ }^{2}$ Clinicians and radiologists should consider this possibility while interpreting massive cardiomegaly on chest radiographs.

\section{Learning points}

Biatrial enlargement can present as massive cardiomegaly on a chest radiograph.

- Common causes of biatrial enlargement include restrictive cardiomyopathy, rheumatic heart disease and constrictive pericarditis.

- Two-dimensional Doppler echocardiography helps in delineating the definitive diagnosis.

Competing interests None.

Patient consent Obtained.

Provenance and peer review Not commissioned; externally peer reviewed.

\section{REFERENCES}

1 Rogers WR, Wittels B. Extreme bilateral atriomegaly; review of the literature and report of a case. Circulation 1957;15:434-41.

2 Ceylan N, Bayraktaroğlu S, Nalbantgil S, et al. Massive bilateral atriomegaly filling thoracic cavity. Anadolu Kardiyol Derg 2011;11: E1-2. 
Figure 3 (A) Transthoracic echocardiogram in an apical four-chamber view showing sizes of the two atria. (B) Continuous-wave Doppler across the tricuspid valve depicting severe tricuspid stenosis with mild regurgitation. (C)

Continuous-wave Doppler across the mitral valve depicting severe mitral stenosis with mild regurgitation. (D) Continuous-wave Doppler across the aortic valve depicting severe aortic stenosis with mild regurgitation.
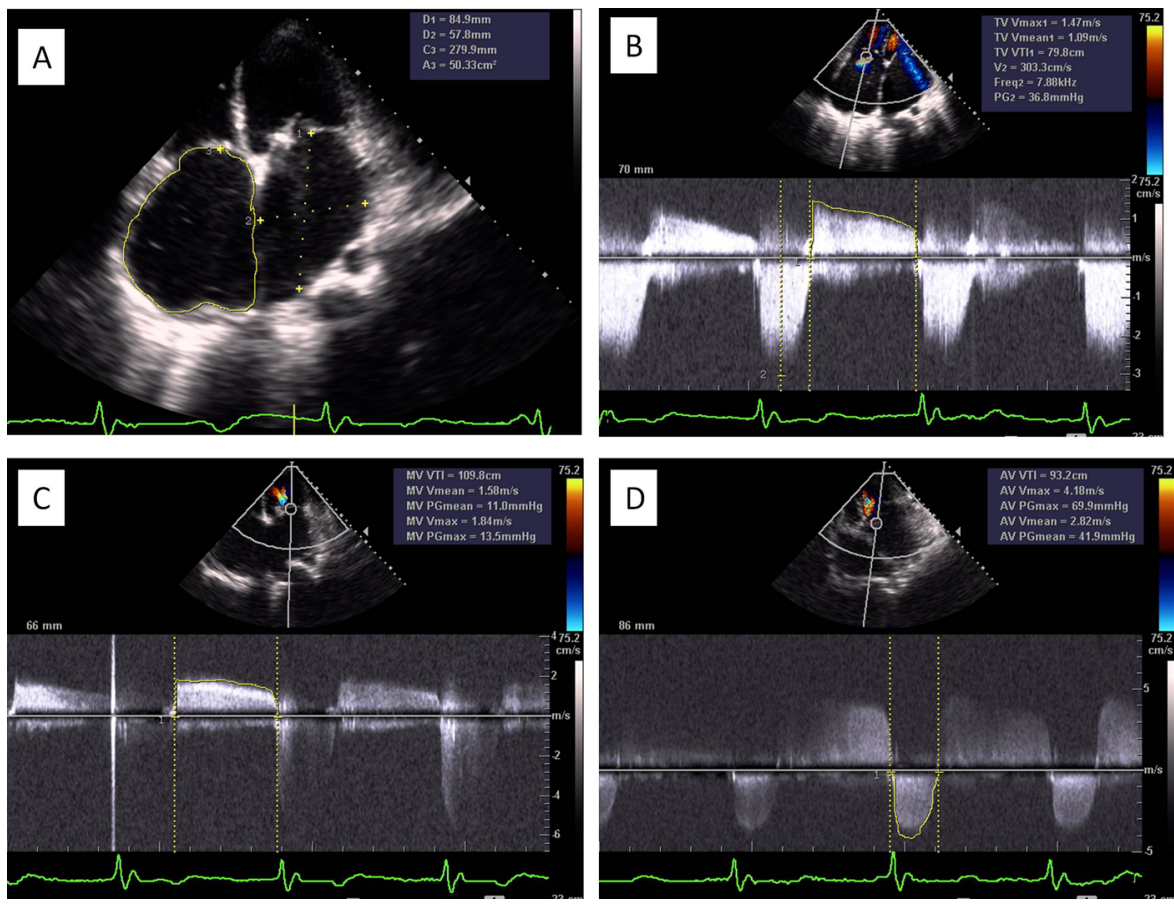

Copyright 2013 BMJ Publishing Group. All rights reserved. For permission to reuse any of this content visit http://group.bmj.com/group/rights-licensing/permissions.

BMJ Case Report Fellows may re-use this article for personal use and teaching without any further permission.

Become a Fellow of BMJ Case Reports today and you can:

- Submit as many cases as you like

- Enjoy fast sympathetic peer review and rapid publication of accepted articles

- Access all the published articles

- Re-use any of the published material for personal use and teaching without further permission

For information on Institutional Fellowships contact consortiasales@bmjgroup.com

Visit casereports.bmj.com for more articles like this and to become a Fellow 